\title{
Year-round Variations in Essential Oil Content and Composition of Male and Female Juniper
}

\author{
Valtcho D. Zheljazkov ${ }^{1}$ \\ University of Wyoming, Sheridan Research and Extension Center, 663 Wyarno \\ Road, Sheridan, WY 82801
}

\section{Tess Astatkie}

Dalhousie University, Faculty of Agriculture, 50 Pictou Road, P.O. Box 550, Truro, Nova Scotia B2N 5E3, Canada

\section{Ekaterina Jeliazkova \\ University of Wyoming, Sheridan Research and Extension Center, 663 Wyarno Road, Sheridan, WY 82801}

Additional index words. Juniperus scopulorum, essential oil, sabinene, alpha-pinene, elemol

\begin{abstract}
Rocky Mountain juniper (Juniperus scopulorum Sarg.) is an evergreen dioecious tree (produces male and female plants). The pleasant aroma and the medicinal value of this species are the result of the essential oil. The hypothesis of this study was that the essential oil content and composition may be different in male and in female trees and also may be affected with seasonal changes throughout the year. The objective was to evaluate yearround variations in essential oil composition of Rocky Mountain juniper within single male and female trees. The concentration of essential oil in fresh leaves varied from $0.335 \%$ to $0.799 \%$, and at most sampling points, the oil content in the biomass of the male tree was greater than that in the biomass of the female tree. There was a trend toward increased essential oil content in male juniper in 220 to 342 days after the first sampling (DAFS), compared with the one in 35 to 184 DAFS. The concentrations of the oil constituents alphapinene, alpha-terpinene, gamma-terpinene, terpinolene, pregeijerene $B$, elemol, betaeudesmol/alpha-eudesmol, and 8-alpha-acetoxyelemol were greater in the oil of the female tree than in the oil of the male tree. Conversely, the concentrations of alpha thujene, sabinene, myrcene, limonene, and delta-cadinene were greater in the oil of the male tree than in the oil of the female tree. However, the concentration gradient trends for both female and male trees were similar for myrcene and sabinene, for alpha-terpinene and terpinolene, for pereijerene $B$ and elemol, and for beta-eudesmol/alpha-eudesmol and 8-alpha-acetoxyelemol. Overall, lower concentrations in the oils at 101 to 132 or 163 DAFS were found for myrcene and alpha-pinene sabinene, whereas the concentrations of gamma-terpinene, elemol (female tree), beta-eudesmol/alpha-eudesmol (female tree), and 8alpha-acetoxyelemol (female tree) were greater during this period. This study demonstrated that the content and composition of the essential oil from Rocky Mountain juniper are subject to seasonal changes and also depend on the sex of the tree.
\end{abstract}

Rocky Mountain juniper (Juniperus scopulorum Sarg.), an evergreen dioecious gymnosperm, is a widespread species in the

Received for publication 30 Apr. 2013. Accepted for publication 29 May 2013

This research was funded by the University of Wyoming startup funding and the Department of Plant Science allocation awarded to Dr. V. Zheljazkov.

We thank Mrs. Adrienne Tatman, Mrs. Burnnie Foulke, Ms. Berva Brock, and Mrs. Leanne Roadifer for their help with the harvesting of the biomass and the extraction of the essential oil in the laboratory. We thank Dr. Mason MacDonald of Dalhousie University and Mrs. Rochelle Koltiska of the University of Wyoming for proof reading the manuscript internally and offering many suggestions.

${ }^{1}$ To whom reprint requests should be addressed; e-mailvjeliazk@uwyo.edu, Valtcho.pubs@gmail. com. western United States (Arizona, Colorado, Idaho, Montana, North Dakota, Nebraska, New Mexico, Nevada, Oklahoma, Oregon, South Dakota, Texas, Utah, Washington, and Wyoming) and is found in Canada and in Mexico (Adams, 2004; Scher, 2002; USDA, 2011). Despite the wide ecological adaption, Rocky Mountain juniper is not a primary source for lumber because of relatively slow growth. However, Rocky Mountain juniper wood is highly valued for its durability, rich color, pleasant aroma, antioxidant activity, and is extensively used for interior paneling, furniture, various novelties, and fence posts. The species has been used extensively in the ethnobotany of native people of North America to treat a number of medical conditions. Native people of North America have been using the leaves as medicine and the wood for preparation of bows, lances, flutes, and other important items (Hart, 1976; Kroeber, 1908). Rocky Mountain juniper is also an important species in the arid and semiarid regions of North America for a number of wildlife species such as deer, elk, small mammals, and birds, which use it for cover and a food source (Rumble and Gobeille, 2013; Scher, 2002). These animals play a major role in seed dispersal.

Rocky Mountain juniper leaves contain a significant amount of strongly aromatic essential oil, which has been subject to some previous studies (Adams and Hagerman, 1977; Adams and Powell, 1976; Cantrell et al., 2013; Zheljazkov et al., 2012a, $2012 b$ ). Previous investigations have found that sexual differences (Adams and Powell, 1976), seasonal changes (Powell and Adams, 1973), diurnal variations (Adams, 1979), and duration of distillation time (Zheljazkov et al., 2012a, 2012b) can affect Rocky Mountain juniper essential oil composition. However, there are no reports on variations of Rocky Mountain juniper essential oil yearround, from within a single tree, and on whether there are any seasonal differences between the composition of essential oil obtained from male and female trees grown side by side. Therefore, the objective of this study was to evaluate year-round variations in essential oil composition of Rocky Mountain juniper within one male and one female trees.

\section{Materials and Methods}

Plant material and essential oil steam distillation. All samples used in this study were generated from two adjacent large Rocky Mountain junipers (tree \#470 male and tree \#471 female) situated at the University of Wyoming Sheridan Research and Extension Center (ShREC) (lat. 44 ${ }^{\circ} 50.373^{\prime}$ $\mathrm{N}$, long. $106^{\circ} 50.396^{\prime} \mathrm{W}$, elevation $1140 \mathrm{~m}$ above sea level). Both trees were planted as part of a windbreak project at ShREC initiated by the U.S. Department of Agriculture in 1915 to 1917. Samples from the two trees were identified as specimens of Rocky Mountain juniper by Ms. Bonnie Heidel, botanist at the Wyoming Natural Diversity Database.

All samples for distillation were generated in early morning $(\approx 0800 \mathrm{HR})$ and distilled fresh. Sample size for each distillation was $500 \mathrm{~g}$ of fresh material in all three replicates. Rocky Mountain junipers (both male and the female trees) were sampled each month starting 12 Apr. 2011 and finishing on 19 Mar. 2012; there were 12 sampling points at the following DAFS: 1, 35, 62, $80,101,132,163,184,220,246,286$, 314 , and 342. These DAFS correspond to 12 Apr. 2011, 17 May 2011, 13 June 2011, 1 July 2011, 22 July 2011, 22 Aug. 2011, 22 Sept. 2011, 13 Oct. 2011, 18 Nov. 2011, 14 Dec. 2011, 23 Jan. 2012, 20 Feb. 2012, and 19 Mar. 2012, respectively.

The steam distillations were conducted as described previously (Zheljazkov et al., 2012a). Briefly, $500 \mathrm{~g}$ of fresh samples (collected at different heights and from different sides of the tree) were chopped into $\approx 2.5-\mathrm{cm}$ pieces and immediately distilled in 2-L steam 
distillation units. The distillation duration of each sample was $360 \mathrm{~min}$, which was based on previous research demonstrating that shorter distillation time may not be sufficient to extract all the oil from Rocky Mountain juniper leaves (Zheljazkov et al., 2012a, $2012 \mathrm{~b}$ ). At the end of each distillation, the oil was collected, separated from the water, measured on analytical scale, and kept in a freezer at $-5{ }^{\circ} \mathrm{C}$ until all distillations were finished. The essential oil content (yield) was calculated by weight, as grams of oil per $100 \mathrm{~g}$ of fresh herbage, and expressed as percentage of oil in the fresh biomass.

Gas chromatography analysis of essential oil. The essential oil samples obtained from Rocky Mountain juniper fresh leaves were analyzed for chemical profile using Hewlett Packard gas chromatograph (GC) Model 6890. The GC column was HP-INNOWAX (crosslinked polyethylene glycol; $30 \mathrm{~m} \times$ $0.32 \mathrm{~mm} \times 0.5 \mu \mathrm{m}$ ), and the flame ionization detector temperature was $275{ }^{\circ} \mathrm{C}$. The GC was fitted with an autosampler, the carrier gas was helium, $40 \mathrm{~cm} \cdot \mathrm{sec}^{-1}, 11.7 \mathrm{psi}\left(60^{\circ} \mathrm{C}\right)$, $2.5 \mathrm{~mL} \cdot \mathrm{min}^{-1}$ constant flow rate; injection was split $60: 1,0.5 \mu \mathrm{L}$, inlet $220^{\circ} \mathrm{C}$; and oven temperature program: $60{ }^{\circ} \mathrm{C}$ for $1 \mathrm{~min}$ $\left(10^{\circ} \mathrm{C} \cdot \mathrm{min}^{-1}\right.$ to $\left.250{ }^{\circ} \mathrm{C}\right)$. The identification of the compounds were obtained by $\mathrm{GC}-$ mass spectroscopy and by comparison of mass spectra with the ones reported in the mass spectral database of the National Institute of Standards and Technology.

Statistical analyses. The effect of sex (female and male) and day $[1,35,62,80$, $101,132,163,184,220,256,286,314$ and 342, with Day 1 being on 12 Apr. 2011 for essential oil (EO) content, and the $12 \mathrm{~d}$ starting on Day 35 for the constituents] on EO content and the concentrations of alphathujene, alpha-pinene, sabinene, myrcene, alpha-terpinene, limonene, gamma-terpinene, terpinolene, 4-terpineol, pregeijerene $\mathrm{B}$, delta-cadinene, elemol, beta-eudesmol/alphaeudesmol, and 8-alpha-acetoxyelemol were determined using a two $\times 13$ factorial for EO content and a two $\times 12$ factorial for the constituents design with three replications. The analysis of variance of all these response measurements was completed using the Mixed Procedure of SAS (SAS Institute Inc., 2010) and further multiple means comparison was completed for significant $(P<$ 0.05 ) effects by comparing the least squares means of the corresponding treatment combinations. For each response, the validity of model assumptions on the error terms was verified by examining the residuals as described in Montgomery (2013).

\section{Results}

The sex of the trees and timing of harvest (DAFS) had a significant effect on the concentration of 4-terpineol in the essential oil (Table 1). The interaction effect of sex and DAFS was significant on the concentration of EO in the fresh biomass (oil content) and on the concentrations of alpha-thujene, alphapinene, sabinene, myrcene, alpha-terpinene, limonene, gamma-terpinene, terpinolene, pregeijerene $\mathrm{B}$, delta-cadinene, elemol, beta-eudesmol/alpha-eudesmol, and 8-alphaacetoxyelemol in the oil (Table 1).

Rocky Mountain juniper EO varied from $0.335 \%$ to $0.799 \%$ (Fig. 1). Overall, at most sampling points, the EO content in the male juniper was higher than that in the female juniper. There was a trend toward increased EO content in male juniper in 220 to 342 DAFS compared with the one in 35 to 184 DAFS; however, this trend was not clearly expressed in the female juniper oil content.

The concentration of alpha-thujene varied from $1.2 \%$ to $2.2 \%$ of the oil and the concentration of alpha-thujene tended to increase in 220 to 342 DAFS compared with 35 to 163 DAFS in both male and female juniper EO (Fig. 1). The concentration of alpha-pinene ( $2.4 \%$ to $7.2 \%$ concentration range in the oil) in some sampling points was greater in the oil from the female tree than in the one from the male tree. The concentration of sabinene varied from $34.8 \%$ to $54.4 \%$ and its concentration at most sampling points was higher in the oil from the male tree than in the oil from the female tree (Fig. 1). Overall, the concentration of sabinene in the oil of both male and female trees was low at 132 to 163 DAFS and higher at 220 to 342 DAFS. The concentration of myrcene varied from $0.7 \%$ to $2.0 \%$ of the oil. Overall the oil from the male tree had higher concentrations of myrcene than the oil from the female tree (Fig. 1). The concentration of alpha-terpinene varied from $2.13 \%$ to $3.43 \%$. In most sampling points, the concentration of alpha-terpinene in the oil from the female tree was higher than in the oil from the male tree. Alpha-terpinene in the oil at 163 DAFS was higher than in the oils sampled at other points within a female or a male tree (Fig. 1).

The concentration of limonene varied from $3.2 \%$ (oil from the female at 35 DAFS) to $5.1 \%$ (in the oil of the male tree at 80,132 , or 163 DAFS) (Fig. 2). At most sampling points, limonene concentration in the oil of the male tree was higher than in the oil from the female tree. The concentration of gammaterpinene varied between $3.7 \%$ and $5.9 \%$ of the oil and was generally higher in the oil from the female tree (Fig. 2). Gamma-terpinene

Table 1. Analysis of variance $P$ values for the main and interaction effects of sex and day on essential oil (EO) content and the concentrations of alpha-thujene (alpha-th.), alpha-pinene (alpha-p.), sabinene myrcene, alpha-terpinene (alpha-t.), limonene, gamma-terpinene (gamma-t.), terpinolene, 4-terpineol, pregeijerene B, delta-cadinene (delta-c.), elemol, beta-eudesmol/alpha-eudesmol, and 8-alphaacetoxyelemol (8-alpha-a.). ${ }^{\mathrm{z}}$

\begin{tabular}{lccccc}
\hline Source of variation & Essential oil content & Alpha-th. & Alpha-p. & Sabinene & Myrcene \\
\hline Sex & 0.001 & 0.001 & 0.001 & 0.001 & 0.001 \\
Day & 0.001 & 0.001 & 0.001 & 0.001 & 0.001 \\
Sex*day & $\mathbf{0 . 0 0 1}$ & $\mathbf{0 . 0 1 1}$ & $\mathbf{0 . 0 0 1}$ & $\mathbf{0 . 0 0 1}$ & $\mathbf{0 . 0 0 1}$ \\
Source of variation & Alpha-t. & Limonene & Gamma-t. & Terpinolene & 4-terpineol \\
Sex & 0.001 & 0.001 & 0.001 & 0.001 & $\mathbf{0 . 0 0 1}$ \\
Day & 0.001 & 0.001 & 0.001 & 0.001 & $\mathbf{0 . 0 0 1}$ \\
Sex*day & $\mathbf{0 . 0 0 1}$ & $\mathbf{0 . 0 0 1}$ & $\mathbf{0 . 0 0 1}$ & $\mathbf{0 . 0 0 2}$ & 0.647 \\
Source of variation & Pregeijerene B & Delta-c. & Elemol & Beta-e. & 8 -alpha-a. \\
Sex & 0.001 & 0.001 & 0.001 & 0.001 & 0.001 \\
Day & 0.001 & 0.001 & 0.001 & 0.001 & 0.001 \\
Sex*day & $\mathbf{0 . 0 0 1}$ & $\mathbf{0 . 0 0 3}$ & $\mathbf{0 . 0 2 1}$ & $\mathbf{0 . 0 2 0}$ & $\mathbf{0 . 0 2 2}$ \\
\hline
\end{tabular}

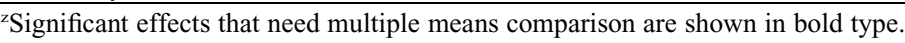

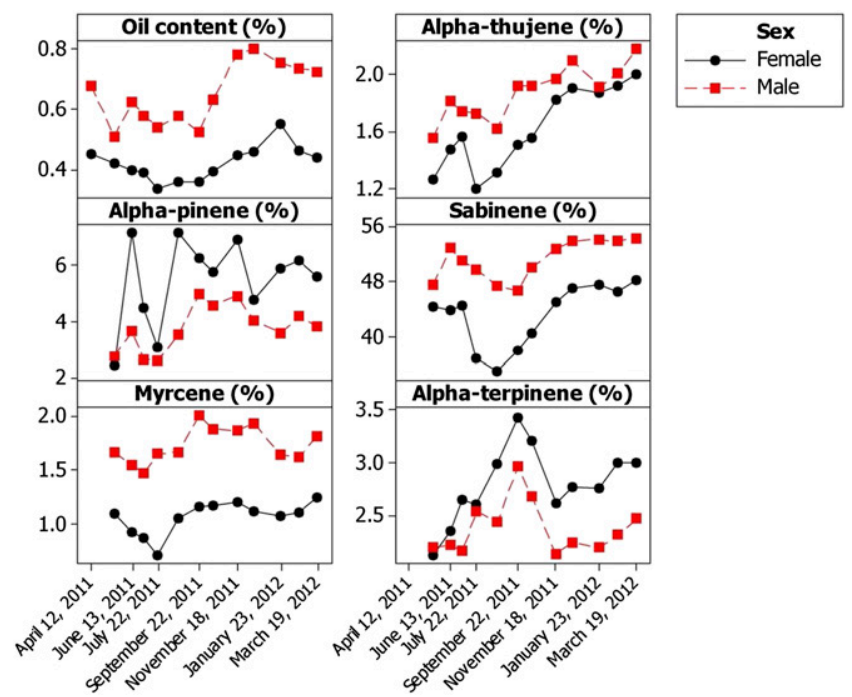

Fig. 1. Plot of essential oil content (\%) and the concentrations (\%) of five constituents at the 12 harvest dates measured from female and male juniper trees. 
concentration was generally greater in the oil at 163 DAFS and relatively lower in the respective oil samples obtained at 35 DAFS and again at 220 to 286 DAFS (Fig. 2). Tepinolene concentration in the oil samples varied between $1.3 \%$ and $2.0 \%$. At most sampling points, terpinolene concentration was greater in the oil samples from the female tree than in the oil from the male tree. The concentration of peregeijerene $\mathrm{B}$ in the oil samples varied from $2.5 \%$ to $7.8 \%$ and at most sampling points was higher in the oil samples from the female tree than in the oil from the male tree (Fig. 2). The concentration of delta-cadinene in the oil samples varied from $0.8 \%$ to $1.8 \%$ and at most sampling points was greater in the oil from the male tree (Fig. 2). Elemol concentration in the oil samples varied from $3.8 \%$ to $8.9 \%$; and at most sampling points, it was higher in the oil of the female tree than in the oil of the male tree (Fig. 2).

The concentration of beta-eudesmol and alpha-eudesmol in the oil samples varied from $1.6 \%$ to $3.0 \%$ and at some sampling points was greater in the oil from the female tree than in the oil from the male tree (Fig. 3). The concentration of 8-alpha-acetoxyelemol varied from $2.4 \%$ to $7.8 \%$ in the oil; at most sampling points, its concentration was greater in the oil of the female tree than in the oil of the male tree (Fig. 3).

The concentration of 4-terpineol varied from $4.2 \%$ to $5.9 \%$ (data not shown) and was higher at 163 DAFS and lower at 35 to 65 and at 342 DAFS. Overall, the average concentration of 4-terpineol was $5.11 \%$ in the oil of the female tree and $4.62 \%$ in the oil of the male tree.

\section{Discussion}

This study demonstrated that there are seasonal differences in EO content and composition within male or female trees. Also, at any given sampling point, the concentration of some oil constituents may be higher in the oil from the female trees, whereas the concentration of other oil constituents may be high in the oil of male trees.
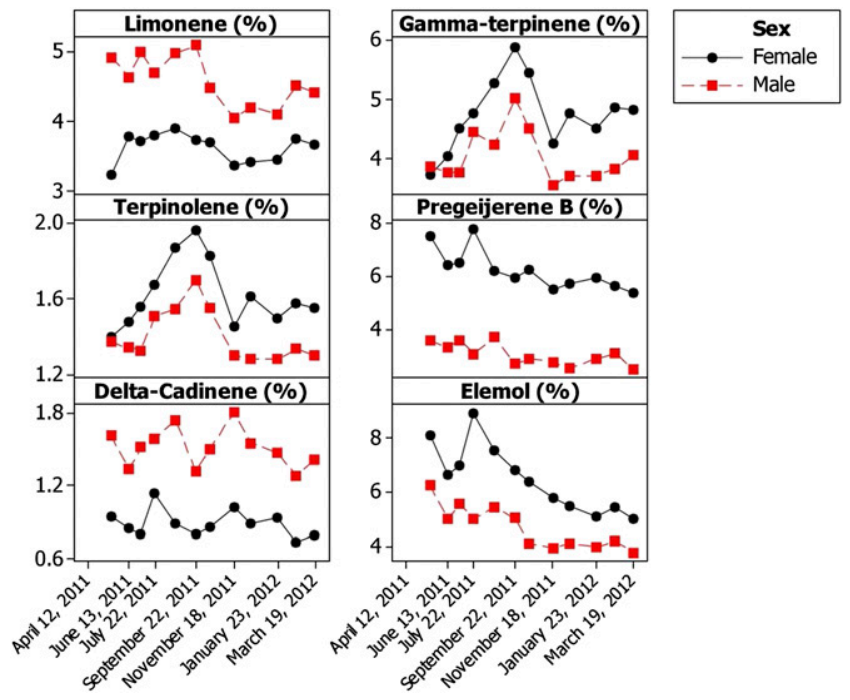

Fig. 2. Plot the concentrations (\%) of six constituents at the 12 harvest dates measured from female and male juniper trees.

There are some previous studies on seasonal variations in the EP composition of Rocky Mountain juniper (Adams and Powell, 1976; Powell and Adams, 1973). For example, Powell and Adams (1973) sampled Rocky Mountain junipers in Colorado at 14 sampling points; the authors stored the material at $0{ }^{\circ} \mathrm{C}$ until distillation (the distillation duration was $24 \mathrm{~h}$ ). However, the authors in Powell and Adams (1973) used ether as a solvent, whereas typically, steam distillation is used to extract essential oil from junipers. Most of the EO constituents in Powell and Adams (1973) were identified in groups of two to three compounds, which make comparisons with the results from the current study difficult.

In Adams and Powell (1976), the authors found that most of the variation in EO composition was the result of growing season; the authors reported very few differences in EO composition as a result of sexual differences. Also, there are some compositional differences between the oil reported in Adams and Powell (1976) and this study. For example, the alpha-terpinene in Adams and Powell (1976) was $1.9 \%$ and $1.5 \%$ in the male and female trees, respectively, whereas in our study, the concentration of the same constituent varied between $2.1 \%$ and $3.4 \%$. Also, in Adams and Powell (1976), gammaterpinene was reported to be $3.3 \%$ and $2.6 \%$, whereas in this study, the variation of the same constituent in the oil was between 3.7\% and 5.9\%. However, in Adams and Powell (1976), the concentration of 4-terpineol was $6.7 \%$ and $5.3 \%$, whereas in this study, the concentration of 4-terpineol was $4.6 \%$ and $5.1 \%$ in the male and female trees, respectively.

The concentration of individual constituents in the male and female junipers in this study was similar to the recently reported essential oil constituents of male (Zheljazkov et al., 2012b) and female (Zheljazkov et al., 2012a) Rocky Mountain juniper studies from the same location. However, the distillation time in Zheljazkov et al. (2012a, 2012b) had a much greater effect on the concentration of individual oil constituents than the effects of sampling date and tree sexes in this study.
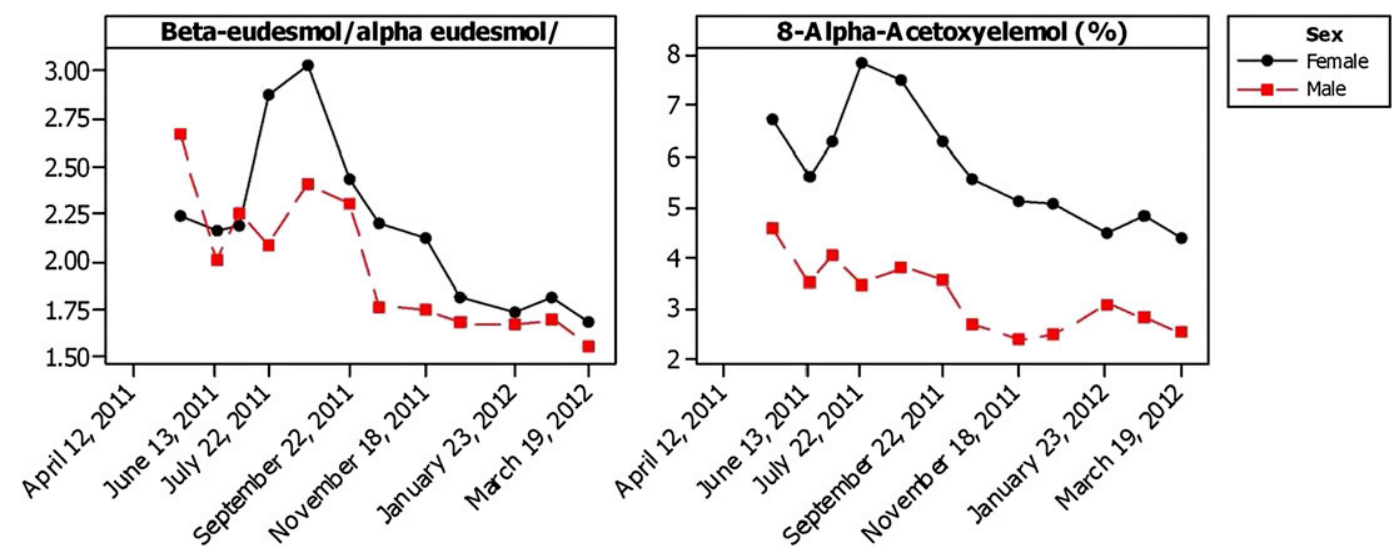

Fig. 3. Plot of the concentrations (\%) of two constituents at the 12 harvest dates measured from female and male juniper trees. 


\section{Conclusions}

Overall, in most sampling points, the oil content in the biomass of male tree was greater than in the biomass of the female tree.

The concentrations of the following oil constituents: alpha-pinene, alpha-terpinene, gamma-terpinene, terpinolene, pregeijerene $\mathrm{B}$, elemol, beta-eudesmol/alpha-eudesmol, and 8-alpha-acetoxyelemol were greater in the oil of the female tree than in the oil of the male tree. Conversely, the concentrations of alpha thujene, sabinene, myrcene, limonene, and delta-cadinene were greater in the oil of the male tree than in the oil of the female tree.

Overall, similar concentration gradient trends for the female and male trees were observed for myrcene and sabinene, for alpha-terpinene and terpinolene, for pereijerene B and elemol, and for beta-eudesmol/ alpha-eudesmol and 8-alpha-acetoxyelemol.

Overall, lower concentration in the oil samples at 101 to 132 or 163 DAFS was found for myrcene, alpha-pinene, and sabinene, whereas the concentrations of gammaterpinene, elemol (oil from the female tree), beta-eudesmol/alpha-eudesmol (female tree), and 8-alpha-acetoxyelemol (female tree) were greater during this period.

\section{Literature Cited}

Adams, R.P. 1979. Diurnal variation in the terpenoids of Juniperus scopulorum (Cupressaceae)Summer versus winter. Amer. Bot. 66:986-988.

Adams, R.P. 2004. Junipers of the world: The genus Juniperus. Trafford Publ., Vancouver, British Columbia, Canada.

Adams, R.P. and A. Hagerman. 1977. Diurnal variation in the volatile terpenoids of Juniperus scopulorum (Cupressaceae). Amer. J. Bot. 64:278-285.

Adams, R.P. and R.A. Powell. 1976. Seasonal variation of sexual differences in the volatile oil of Juniperus scopulorum. Phytochemistry 15:509-510.

Cantrell, C.L., V.D. Zheljazkov, W.A. Osbrink, A. Castro, V. Maddox, L.E. Craker, and T. Astatkie. 2013. Podophyllotoxin and essential oil profile of Juniperus and related species. Ind. Crops Prod. 43:668-676.

Hart, J.A. 1976. Montana native plants and early peoples. Montana Historical Society, Helena, MT.

Kroeber, A.L. 1908. The ethnology of the Gros Ventre. American Museum of Natural History. Anthropological Papers 1:145-281.

Montgomery, D.C. 2013. Design and analysis of experiments. 8th Ed. Wiley, New York, NY.
Powell, R.A. and R.P. Adams. 1973. Seasonal variation in the volatile terpenoids of Juniperus scopulorum (Cupressacae). Amer. J. Bot. 60: 1041-1051.

Rumble, M.A. and J.E. Gobeille. 2013. Wildlife associations in the Rocky Mountain juniper in the northern great plants, South Dakota. 28 May 2013.<http://www.fs.fed.us/rm/pubs_rm/ rm_gtr258/rm_gtr258_080_090.pdf>.

SAS Institute Inc. 2010. SAS/STAT ${ }^{\circledR} 9.3$ user's guide. SAS Institute Inc., Cary, NC.

Scher, J.S. 2002. Juniperus scopulorum. In: Fire effects information system [online]. U.S. Department of Agriculture, Forest Service, Rocky Mountain Research Station, Fire Sciences Laboratory (producer). Apr. 2013. <http://www.fs. fed.us/database/feis/>.

USDA. 2011. Natural Resources Conservation Service. Plants profile: Juniperus scopulorum Sarg., Rocky Mountain juniper. Apr. 2013. $<$ http://plants.usda.gov/java/profile?symbol= JUSC $2>$.

Zheljazkov, V.D., T. Astatkie, E. Jeliazkova, A.O Tatman, and V. Schlegel. 2012a. Distillation time alters essential oil yield, composition and antioxidant activity of female Juniperus scopulorum trees. J. Essent. Oil Res. 25:62-69.

Zheljazkov, V.D., T. Astatkie, E.A. Jeliazkova, and V. Schlegel. 2012b. Distillation time alters essential oil yield, composition, and antioxidant activity of male Juniperus scopulorum trees. J. Oleo Sci. 61:537-546. 